\title{
Use of Waste Road-Asphalt as Aggregate in Pavement Block Production
}

\author{
B. Mohammed ${ }^{1, *}$, A. M. Ali ${ }^{1}$, S. Ibrahim ${ }^{1}$ and B. A. Umdagas ${ }^{2}$ \\ ${ }^{1}$ Department of Agricultural and Environmental Resources Engineering, Faculty of Engineering, University of \\ Maiduguri, PMB 1069 Maiduguri, Nigeria \\ ${ }^{2}$ Department of Civil and Water Resources Engineering, Faculty of Engineering, University of Maiduguri, PMB \\ 1069 Maiduguri, Nigeria
}

\begin{abstract}
This research investigated the possibility of replacing coarse and fine aggregates with waste roadasphalt (RWA), when sieved appropriately, in concrete production. Interlock pavement block is used widely in many parts of the world as modern-day solution to outdoor flooring applications. The weight-percentage replacements of both coarse and fine aggregates with RWA at 0\%, 10\%, 20\%, 30\%, 40\%, 50\%, 60\%, 70\%, 80\% and $90 \%$ respectively using a concrete mix ratio of 1:2:4 and water-to-cement ratio of 0.45 were carried out. The interlock block samples produced were then cured for 28days. Unconfined compressive strength (UCS) and the water absorption properties of the samples were then tested. Comparison of the results of the RWA-containing samples to those of the respective control samples show significant benefits of using RWA in interlock block production. UCS results of RWA-containing samples compared well with those of the control samples and the $R W A$ content also influenced the lowering of the water absorption of the samples. Overall, the research shows that it is possible to replace both coarse and fine aggregates with RWA materials, when sieved appropriately, hence indicating that RWA could be recycled beneficially.
\end{abstract}

Keywords: Aggregate, block-production, pavement, road-asphalt, use, waste.

\section{Introduction}

Asphalt is a sticky black and highly viscous liquid or semi-solid present in most petroleum, it is a substance classified as pitch. The primary use of asphalt is in road construction where it is used as the glue or binder mixed with aggregate particles to create asphalt concrete. It is also used in bituminous waterproofing products including roofing felts and sealing flat roofs. Naturally occurring asphalt is called crude bitumen.

The great majority of asphalt used commercially is obtained from petroleum. Nonetheless, large amounts of asphalt occur in concentrated form in nature. It is often reported that naturally occurring deposits of asphalt/bitumen are formed from the remains of ancient, microscopic algae and other once-living things.

Due to the advancement in technology and research, researchers have always craved on how waste materials could be used in many sectors so as to maintain nature and beauty and also to reduce cost of raw materials. Governments have been clamoring for the use of local materials in the construction industry so as to limit cost and make it affordable for their citizens. Also there are discoveries of how waste materials could be recycled and produced in proper manners and good management. In this regard, many works have carried out with a view to replacing fine and coarse aggregates in concrete. Such works have been published in journals and other serials as well as on the internet.

Materials such as palm kernel shell, glass fly-ash, tile (Shafigh et al., 2010; Kim et al., 2016) and others have been used so far to partially replace coarse aggregates successfully. But so far no known work has been published on the use of waste road-asphalt (WRA) for the partial replacement of coarse and fine aggregates in interlock block production. This is a key driver in this research. 
The overall objective of the study was to investigate the possibility of using waste-road-asphalt as a partial replacement for coarse aggregate in concrete Interlock block production.

\subsection{Concrete}

Concrete is a composite construction material composed primarily of aggregates (fine and coarse), cement and water (Neville, 1996). There are several formulations with varied properties. The aggregate is generally coarse gravel or crushed rock such as limestone, granite along with fine aggregate such as sand. The cement on the other hand is commonly Portland cement and other constituents such as fly ash and slag cement that helps in binding the aggregate (Stellaci, 2009). Concrete technology was known by the ancient Romans and was widely used within the Roman Empire. The word concrete was derived from the word 'concretus' meaning compact or condensed (Lancaster, 2005). Based on composition, there are several types of concrete available, created by varying the proportion of their ingredients. In this way, or by substitution for the cementations and aggregate phases, the finished product can be tailored to its application with varying strength, density or chemical and thermal resistance properties. The mix design depends on the type of structure being built, how the concrete will be mixed and delivered and how it will be placed to form this structure.

\subsubsection{Aggregates}

Aggregate is a broad category of coarse particulate material used in construction, including sand, gravel, crushed stone, slag, recycled concrete and geo-synthetic aggregates. Aggregates are the most mined materials in the world. Aggregates are a component of composite materials such as concrete and asphalt concrete; the aggregate serves as reinforcement to add strength to the overall composite material. Sources for these basic materials can be grouped into three main areas: Mining of mineral aggregate deposits, including sand, gravel, and stone; use of waste slag from the manufacture of iron and steel; and recycling of concrete, which is itself chiefly manufactured from mineral aggregates. In addition, there are some (minor) materials that are used as specialty lightweight aggregates: clay, pumice, perlite, and vermiculite.

Aggregates consist of both fine and coarse aggregates. They make up bulk of a concrete mixture. Sand, natural gravel and crushed stone are used mainly for this purpose. Recycled aggregate (from constructions 'demolitions and excavation waste) are increasingly used as partial replacement of natural aggregates while a number of manufactured aggregates are also used including air cooled blast furnace slag and bottom ash are also permitted. For good concrete mix, aggregates needed to be clean, hard, strong particles free of absorbed chemicals or coatings of clay and other fine materials that could cause deterioration of concrete. Fine aggregates generally consist of natural sand or crushed stone with most particles passing through the $(9.5 \mathrm{~mm})$ sieve. Coarse aggregates are particles greater $4.75 \mathrm{~mm}$, but generally range between $9.5 \mathrm{~mm}$ to $37.5 \mathrm{~mm}$. Gravels constitutes the majority of coarse aggregates used in concrete with crushed stone making must of remainder. Aggregates processing consists of crushing, screening and washing the aggregates to obtain proper cleanliness and gradation. There have been many works in which wastes materials beneficially used in concrete (Dhadse et al., 2008; Hernandez et al., 1998; Kruger and Adam, 2013; Mangialardi, 1999; Mohammed et al., 2013; Omange, 2001).

\subsubsection{Coarse and Fine Aggregates Replacements}

During road rehabilitation the block were removed or scrapped and it contain asphalt and gravel mixed together forming asphalt concrete (Oglesby and Hicks, 1982). After it was parked, crushed and processed, the particles undergo sieving using the $2 \mathrm{~mm}$ and $4 \mathrm{~mm}$ sieves and the particles retained (coarse aggregate) was then used as the sample to be replaced (BS 410: 1986). 

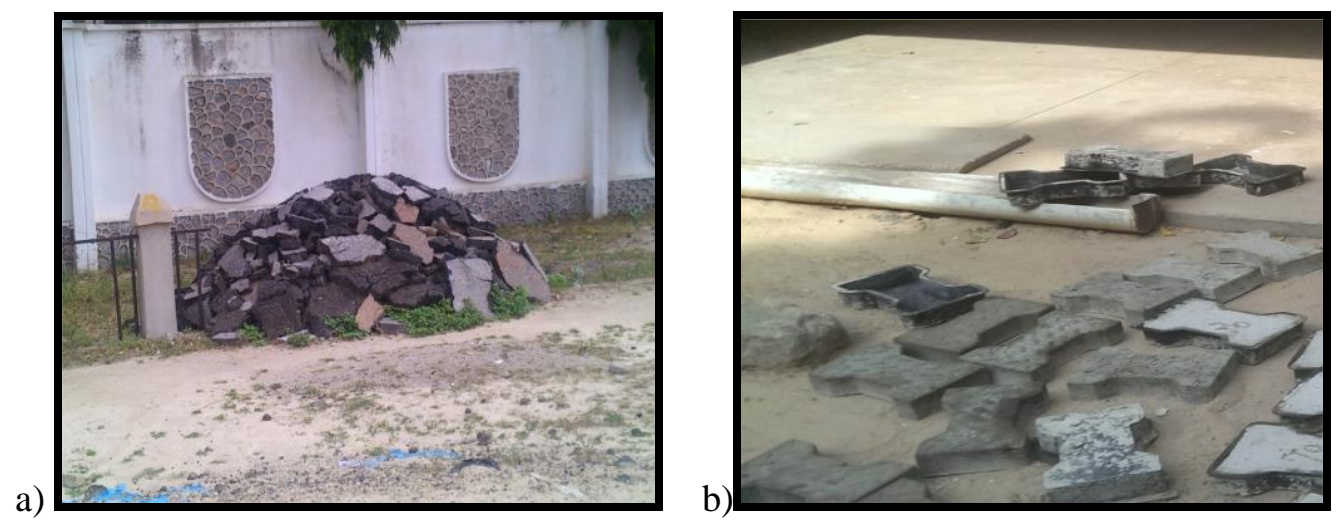

Fig. 1: a) A heap of sample of the waste road asphalt (WRA); and b) Moulds and samples of the interlock blocks produced using the WRA.

\section{Experimental Methods}

\subsection{Materials and Experimental Procedures}

The following were the sequence of procedures used in carrying out this study:

Sourcing of the waste road-asphalt (and other materials) in Maiduguri, Nigeria and storing the solid waste materials; crushing and sieving the waste materials using a $2 \mathrm{~mm}$ and $4 \mathrm{~mm}$ laboratory sieves (i.e. fine and coarse separations); mixing of the coarse aggregate obtained with fine sand, cement and water at a ratio of 1:2:4; varying the waste asphalt contents (i.e. coarse and fine aggregates) from $0-90 \%$ in the mix before production and casting of the concrete interlock block in moulds; de-molding of the block after 24hrs of casting; curing of the block for 28 days at a room temperature of about $30^{\circ} \mathrm{C}$; weighing of the cured block; air drying of the cured block in the laboratory for 24 hours; weighing of the air dried block to examine the weight difference; conducting water absorption test to determine that property; and testing for unconfined compressive strength.

\subsection{Mix Design}

The mix ratio used was 1:2:4 (cement: fine-aggregate:coarse-aggregate). The water to cement ratio used was 0.45 and the aggregate to cement ratio was 6:1. This mix was ensured for all the concrete interlock block as replacements of the fine and coarse aggregates was carried out at 0, 10, 20, 30, 40, 50, 60,70, 80 and $90 \%$ respectively.

a )

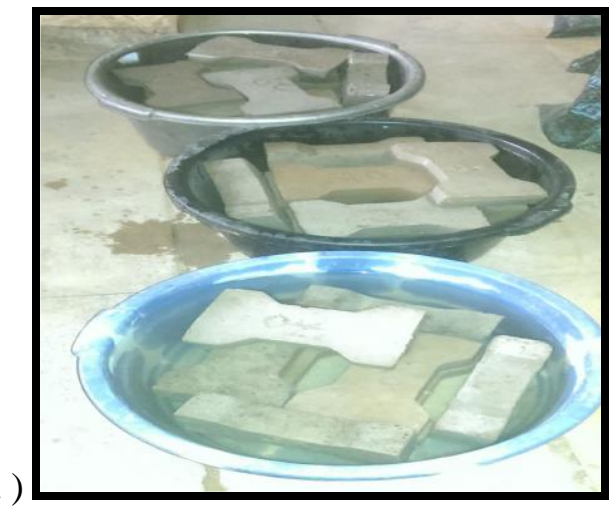

b)

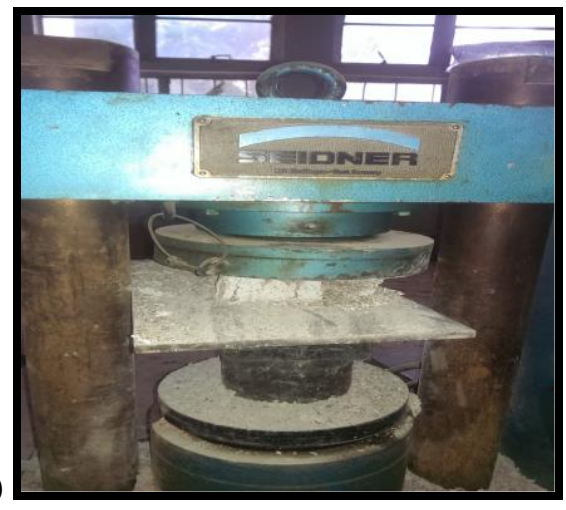

Fig. 12: a) Test for water absorption of the blocks; and b) Test for unconfined compressive strength of the blocks.

\subsection{Unconfined Compressive Strength Test}

Unconfined compressive strength (UCS) was determined using a universal compressive test machine (Seidner, 794 Riedlingen-West, Germany) with a capacity of 2,000KN in accordance with BS 12390-3:2002 on the block samples. 


\subsection{Water Absorption Test}

Water absorption was determined in accordance with BS 1881-122: 1983. The procedure involves immersion of block samples in water at least $125 \mathrm{~mm}$ deep for 24 hours, with the water surface kept at $25 \pm 5$ $\mathrm{mm}$ above the top of the block. The blocks were then removed, excess surface water dried with a damp absorbent cloth and the sample weighed. The difference between the initial dry weight and the saturated weight gives the water absorption according to the formula:

Where:

$$
\left[\frac{\left(w_{s a t}-w_{d r y}\right)}{w_{d r y}}\right] \times 100 \%
$$

$\mathrm{W}_{\text {sat }}=$ the saturated weight of the specimen $(\mathrm{g})$; and $\mathrm{W}_{\mathrm{dry}}=$ the initial dry weight of the specimen $(\mathrm{g})$

\section{Results and Discussions}

\subsection{Results}

The results of the research are presented in Tables 1 to 4 below. Each interlock block has an area of $0.026 \mathrm{~m}^{2}$ and a volume of $0.00143 \mathrm{~m}^{3}$.

TABLE I: Density and Unconfined Compressive Strength Data of Interlock Block Samples Containing Coarse WRA at 28days Curing.

\begin{tabular}{|c|c|c|c|}
\hline $\begin{array}{c}\text { Percentage Replacement of Coarse } \\
\text { Aggregate with Waste Road Asphalt } \\
(\mathbf{\%})\end{array}$ & $\begin{array}{c}\text { Weight of interlock } \\
\text { block } \\
(\mathbf{K g})\end{array}$ & $\begin{array}{c}\text { Density of interlock } \\
\text { block } \\
\left(\mathbf{K g} / \mathbf{m}^{\mathbf{3}}\right)\end{array}$ & $\begin{array}{c}\text { Unconfined Compressive } \\
\text { Strength } \\
\text { (MPa) }\end{array}$ \\
\hline 0 & 3.18 & 2.23 & 17 \\
\hline 10 & 2.95 & 2.03 & 20 \\
\hline 20 & 3.10 & 2.17 & 17 \\
\hline 30 & 3.09 & 2.17 & 17 \\
\hline 40 & 3.11 & 2.17 & 14 \\
\hline 50 & 2.98 & 2.09 & 14 \\
\hline 60 & 2.93 & 2.05 & 13 \\
\hline 70 & 2.87 & 2.00 & 12 \\
\hline 80 & 2.98 & 2.08 & 12 \\
\hline 90 & 2.97 & 2.07 & 12 \\
\hline
\end{tabular}

TABLE 2: Water Absorption Data of Interlock Block Samples Containing Coarse WRA.

\begin{tabular}{|c|c|c|c|c|c|c|c|c|c|c|}
\hline $\begin{array}{c}\text { Percentage Replacement of } \\
\text { Coarse Aggregate with Waste } \\
\text { Road Asphalt (\%) }\end{array}$ & 0 & 10 & 20 & 30 & 40 & 50 & 60 & 70 & 80 & 90 \\
\hline Water Absorption (\%) & 3.0 & 3.8 & 4.8 & 5.6 & 6.4 & 6.2 & 7.2 & 7.5 & 7.7 & 8.8 \\
\hline
\end{tabular}

TABLE 3: Density and Unconfined Compressive Strength Data of Interlock Block Samples Containing Fine WRA at 28days Curing.

\begin{tabular}{|c|c|c|c|}
\hline $\begin{array}{c}\text { Percentage Replacement of Coarse } \\
\text { Aggregate with Waste Road Asphalt } \\
(\mathbf{\%})\end{array}$ & $\begin{array}{c}\text { Weight of interlock } \\
\text { block } \\
(\mathbf{K g})\end{array}$ & $\begin{array}{c}\text { Density of interlock } \\
\text { block } \\
\left(\mathbf{K g} / \mathbf{m}^{\mathbf{3}}\right)\end{array}$ & $\begin{array}{c}\text { Unconfined Compressive Strength } \\
\text { (MPa) }\end{array}$ \\
\hline 0 & 3.05 & 2.133 & 10.50 \\
\hline 10 & 3.00 & 2.098 & 15.90 \\
\hline 20 & 3.25 & 2.273 & 19.70 \\
\hline 30 & 3.10 & 2.168 & 18.90 \\
\hline 40 & 3.20 & 2.238 & 14.76 \\
\hline 50 & 3.10 & 2.168 & 14.08 \\
\hline 60 & 3.00 & 2.098 & 11.86 \\
\hline 70 & 3.10 & 2.168 & 11.56 \\
\hline 80 & 3.00 & 2.098 & 10.70 \\
\hline 90 & 3.10 & 2.168 & \\
\hline
\end{tabular}




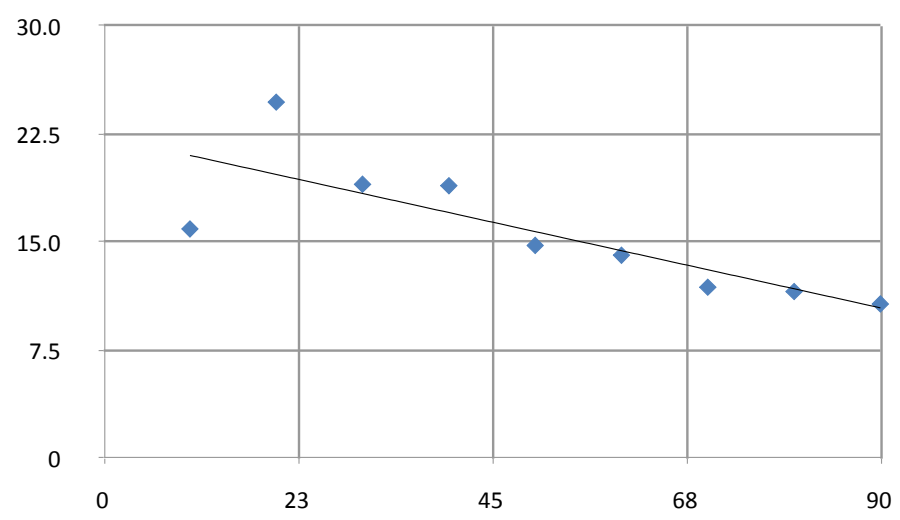

Fig. 3: Data on unconfined compressive strength (y-axix) in relation to \%wt fine WRA content (x-axix).

TABLE 4: Water Absorption Data of Interlock Block Samples Containing Fine WRA.

\begin{tabular}{|c|c|c|c|c|c|c|c|c|c|c|}
\hline $\begin{array}{c}\text { Percentage Replacement of } \\
\text { Coarse Aggregate with Waste } \\
\text { Road Asphalt }(\%)\end{array}$ & 0 & 10 & 20 & 30 & 40 & 50 & 60 & 70 & 80 & 90 \\
\hline Water Absorption (\%) & 8.61 & 3.45 & 4.88 & 4.6 & 5.56 & 5.45 & 5.80 & 6.00 & 6.80 & 7.50 \\
\hline
\end{tabular}

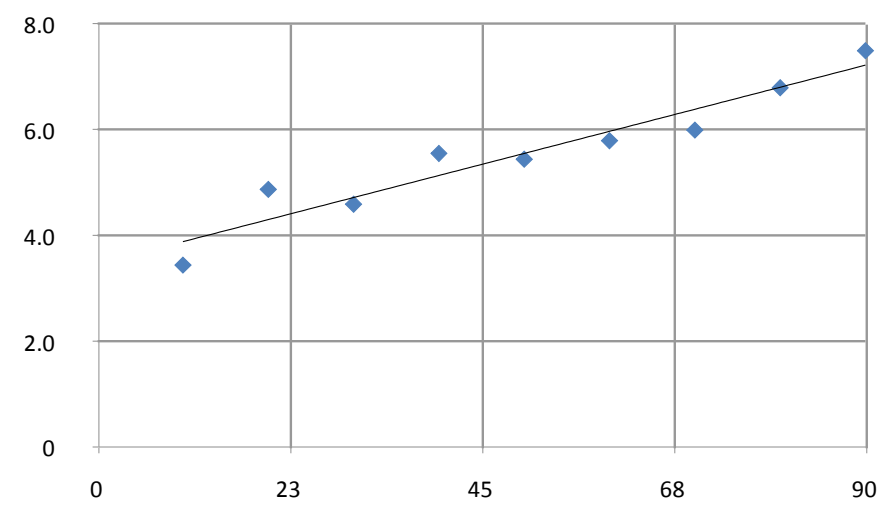

Fig. 4: Data on water absorption (y-axix) in relation to \%wt fine WRA content (x-axix).

\subsection{Discussions}

From the unconfined compressive strength (UCS) data, it can be seen that it is possible to replace the coarse aggregate with the waste road asphalt up to $90 \%$ even though there were considerable reduction in the UCS with increased \%wt content of WRA. However, the best result was obtained at $20 \%$ wt replacement even though at up to $30 \%$ wt replacement the UCS results was comparable to that of the control sample. Overall, the results show that there is a correlation between \%wt WRA replacements and UCS indicating that the higher the \%wt WRA content, the lower the UCS. This could perhaps be due to the fact that with higher coarse WRA, there is an increase in pore spaces that translate to lower density (as shown in the density data) and this has a direct relationship with lower UCS manifestation. This implies that the UCS of the interlock blocks containing the WRA decreases as the \%wt WRA content increases.

Similarly, the UCS decreases with increase in the \%wt fine-aggregate WRA content in relation to the block. The optimum \%wt replacement was achieved at $20 \%$ even though the all the results are higher than that of the control block sample.

As for the water absorption results, it can also be seen that there is a correlation between the \%wt WRA content and the water absorption. The higher the \%wt coarse-aggregate WRA content, the higher the water absorption. This could be perhaps due to the fact that higher \%wt WRA translates to increased pore spaces 
thereby leading to increased water absorption since there is a direct correlation between pore spaces and water absorption.

As for the fine-aggregates replacement, the water absorption increases with increase in the \%wt fineaggregate WRA content in relation to the block. The minimum water absorption was achieved at $10 \%$ even though all the results are lower than that of the control block sample. This might be due to the residual asphalt in the block samples.

\section{Conclusions}

On the basis of this research it can be concluded that it is possible to use waste road asphalt as a substantial replacement for conventional coarse and fine aggregates in concrete interlock block production when the experiment procedure used in this research is adopted. This is a very encouraging outcome since it would lead to reduction in overdependence on the natural/conventional fine and coarse aggregates as well as a reduction of their exploitation. It would as well have good environmental benefits both ways and an economic benefit too.

Further work is recommended in order to assess the stability and durability of the block samples produced.

\section{References}

[1] Adam M. Neville, Properties of Concrete, John Wiley and Sons, United Kingdom, 1996, 844p.

[2] P. Shafigh, M. Z. Jumaat and H. Mahmud, Mix design and mechanical properties of oil palm shell lightweight aggregate concrete: a review”, International Journal of Physical Sciences, vol. 5(14), 2010, pp. 2127-2134.

[3] Kim Hung Mo, U. Johnson Alengaram, Mohd Zamin Jumaat, Michael Yong Jing Liu and James Lim "Assessing some durability properties of sustainable lightweight oil palm shell concrete incorporating slag and manufactured sand", Jounal of Cleaner Production, vol. 112(1), 2016, pp. 763-770.

https://doi.org/10.1016/j.jclepro.2015.06.122

[4] P. Stellaci, L. Liberti, M. Notarnicola and P. L. Bishop, "Valorization of coal fly ash by mechano-chemical activation: Part I. Enhancing adsorption capacity", Chemical Engineering Journal, vol. 149(1-3), 2009, pp. 11-18. https://doi.org/10.1016/j.cej.2008.06.043

[5] Lynne C. Lancaster, Concrete vaulted construction in imperial Rome: Innovations in context, Cambridge University Press, Cambridge, UK, 2005, 274 p.

[6] S. Dhadse, P. Kumari, L. J. Bhagia, "Fly ash characterization, utilization and government initiatives in India - A review”, J. Sci. Ind. Res., vol. 67, 2008 pp. 11-18.

[7] J. F. Hernandez, Middendorf B. Martirena, M. Gehrke, and H. Budelmaun, "Use of wastes of the sugar Industry as pozzolona in lime pozzolana Binders: Study of Reaction”, Cement and Concrete Res., vol 28(11), 1998, pp. 1528-1536.

[8] O. Kruger, and C. Adam, "Sewage sludge ashes-composition, mass flows and recovery potential", in: R. Cossu, P. He, P. Kjeldsen, Y. Matsufuji, D. Reinhart and R. Stegmann (eds.), Proceedings of Fourteenth International Waste Management and Landfill Symposium (SARDINIA 2013). Sardinia, Italy, 30 September - 4 October, 2013.

[9] T. Mangialardi, A. E. Paolini, A. Polettini and P. Sirini, "Optimization of the solidification/stabilization process of MSW fly ash in cementitious matrices", J. Hazard. Mater., vol. 70, 1999, pp. 53-70. https://doi.org/10.1016/S0304-3894(99)00132-6

[10]B. Mohammed, C. O. Ezimah and B. A. Umdagas, "Use of neem leaf ash as cement alternative in concrete production”, in: R. Cossu, P. He, P. Kjeldsen, Y. Matsufuji, D. Reinhart and R. Stegmann (eds.), Proceedings of Fourteenth International Waste Management and Landfill Symposium (SARDINIA 2013). Sardinia, Italy, 30 September - 4 October, 2013, pp. 368.

[11]C. H. Oglesby and R. G. Hicks, Highway Engineering, $4^{\text {th }}$ Edition, John Wiley and Sons, New York, USA, 1982, pp. $683-685$.

[12]BS 410: 1986: Specification for test sieves. British Standards Institution, London, UK.

[13] G. N. Omange, "Palm kernel shell as road and building material" Technical Transactions of The Nigerian Society of Engineers, 36 (1), 2001, pp17 -25.

[14]BS 12390-3: 2002. Testing hardened concrete Part 3: Compressive strength of test Specimens. British Standards Institution, London, UK. 
[15]BS 1881-122: 1983. Testing concrete Part 122: Method for determination of water absorption. British Standards Institution, London, UK. 